\title{
THE LOCATION PROBLEM OF A PLANT AND A WAREHOUSE BY AN EXPANDED LINEAR PROGRAMMING MODEL INTEGRATED WITH AHP
}

\author{
Assist.Prof.Dr. Yiğit KAZANÇOĞLU, Izmir University of Economics, Faculty of \\ Economics and Administrative Sciences, Department of Business Administration, \\ yigit.kazancoglu@ieu.edu.tr
}

Prof. Dr. Erhan ADA, Izmir University of Economics, Faculty of Economics and Administrative Sciences, Department of Business Administration, erhan.ada@ieu.edu.tr

\begin{abstract}
Plant location models are considered only with the aim of locating the plant with minimization of the related cost items without taking into consideration the location of other facilities. Warehouse location problem can be included in the solution of plant location problem simultaneously to find an integrated investment solution. However the whole system should be considered as a network in accordance with the supply chain concept and the optimization of the overall system should be aimed considering suppliers, plants, warehouses and retailers. The study stands on the systems approach and models the problem as a network considering different parties in the supply chain. Facility location factors are stated and classified as quantitative and qualitative. The integration of Analytical Hierarchy Process and a linear integer programming model is proposed for the location selection of both plant and warehouse.
\end{abstract}

Key Words: Facility location, combination of qualitative and quantitative factors, Linear programming, Analytical Hierarchy Process (AHP)

\section{INTRODUCTION}

Almost every private and public sector faces with the task of locating facilities. For the consideration of Verter and Dincer (1995); this type of work is gaining importance because of the emerging world is going global. Therefore, plants are placed in different countries and different regions. Models developed to analyze facility location decisions for the optimized one or more objectives, 
subject to physical, structural, and policy constraints, governmental implementations, incentives in variety in a static or deterministic setting. As Current, J., Rarick, S., Revelle C. (1998) comments because of the large capital outlays that are involved, facility location decisions are executed in the longterm. Consequently, there may be considerable uncertainty of the parameters of the location decision.

Facility location has an important role because the site selection directly relates with the warehouse systems, inventory control and handling, customers and suppliers. A good location gives a strategic advantage against competitors. To give better service to potential customers by short distancesstated by Jayaraman and Vaidyanathan (1998) as locating more outlets a company enhances its accessibility and hence improves its overall customer service. Kumral M. (2004) said that the determination of a facility location is a well-known phenomenon in operational research area. The facility location means the placement of a planned facility with regard to other facilities according to some constraints. There are both quantitative and qualitative methods applied for the facility location problems explained by Chen and Sha (2001).

\section{FACILITY LOCATION FACTORS}

In real life cases there exist many factors directly or indirectly affect the facility location selection. As global location factors that can be defined as; government stability, governed regulations, political and economic systems, exchange rates, culture, climate, export $\&$ import regulations, tariffs and duties, raw material availability, availability of suppliers, transportation \& distribution systems, labour force, available technology, technical expertise, cross-border trade regulations and group trade agreements.

On the other hand, for the selection of the region, city or country the factors considered are; labour, proximity to customers, market size, construction costs, land cost, availability of modes and quality of transportation, transportation costs, local business regulations, business climate, tax regulations financial services, incentive packages applied to that region and labour force education are both critical and important in facility location selection.

Therefore it is clear that there is a need in location problemapproaches concentrating on the combination of qualitative and quantitative factors.

\section{WAREHOUSE LOCATION}

Warehouse planning and control structure refers to high importance because of storage and pick-up processes. According to Toloken (2000), the growth of 
THE LOCATION PROBLEM OF A PLANT AND A WAREHOUSE BY AN EXPANDED

LINEAR PROGRAMMING MODEL INTEGRATED WITH AHP

warehouse functions to include call centres, light assembly or back-office functions, along with the development of the Internet and better-computerized inventory, are leading companies to have fewer but rises a requirement to larger warehouse and distribution facilities.

Locating facilities and allocating products to these facilities is a huge problem. There is a trade-off between the cost of construction and operating of the facility and the cost of transportation. Low facility costs and high transportation costs implies the decentralization concept. Lead times, customer service and response depend on the warehouses. Therefore, the location of the warehouse is also important as facility location. One part of the Warehouse Management Systems contains also warehouse location. One aim is to minimize the travel or shipment distance as location selection.

In this study the factors of inventory holding cost, fixed cost of locating warehouse, shipping cost from warehouse to the customer is considered. All the calculations are respected according to the qualitative and quantitative constraints of both warehouse and plant.

\section{APPROACHES ON FACILITY LOCATION}

Classical plant location problems have been discussing over the years, as initiating with the work of Weber (1909), however, the workable models are constituted only in the 1960s with the arrival of automatic computation capabilities implied by Laporte and Revelle (1996). Many methods can be applied in facility location problems. One is the metric k-median method used by Arya, N. et al. (2004). It is stated the locality gap of a local search procedure for a minimization problem as the maximum ratio of a locally optimum solution (obtained using this procedure) to the global optimum.

Jungthirapanich and Benjamin (1995) ensures a chronological summary of research studies between the years 1875 to 1990 on general industrial location, implying that, frequently in the past, a limited number of quantitative factors such as transportation and labour costs were considered when firms made a location decision, but that more recently an increasingly wide range of both qualitative and quantitative factors have been evident. Costs are a major concept in many international location decisions and there may be trade-offs between different types of costs. Atthirawong and MacCarthy (2003) states location factors mainly influencing international location decisions.

The location facility problems cover formulations, which is in the range of complexity from simple single commodity linear deterministic model types to the multi commodity nonlinear stochastic versions as suggested by Jayaraman and Vaidyanathan (1998). Hoffman and J Schniederjans (1994) concern that for the 
global expansion strategies of the companies; facility location has an important role. Unfortunately little has been written to aid companies on these strategies.

According to Jayaraman, Vaidyanathan (1998) mathematical models have many benefits for the supply chain network design methodology. They address the questions of how many facilities should be sited, where the location for the facility is and how the location factors affect on this selection.

Considered by P. T. Chuang (2002), QFD approach is used for the facility location factors. Location criteria and weighted factors are all assessed and the model contains location requirements (quality requirements as they respected), location criteria (quality characteristics as they respected), importance weighting of requirement, importance degree of location criteria and normalized degree of location criteria. All of these are schemed in a matrix. The aim is to satisfy whether location requirements and location criteria.

The aim of this paper is to formulate the optimization within the phases of the supply chain members to create an effective and efficient system through the combination of quantitative and qualitative factors. Besides, to explore proposing an integrated model for decision support systems is also significant.

\section{SUPPLY CHAIN NETWORK DEFINITION AND MODELLING}

Supply chain network concept is gaining importance on logistics operations and strategic management. Supply chain is behaved as a network of nodes including suppliers, plants, warehouses and markets. All the members of these four parts are respected as nodes. In supply network, the aim is to focus on the network that is formed by the flow of material, services, and associated information. One could extend the approach towards "technology chains" and "knowledge networks". This approach is mentioned by Mills, Schmitz and Frizelle (2004). Today the manufacturers must find a way to improve their supply chain partners in a way that all of the chain members must ensure flexibility, speed and less costly ways.

Korpela and Lehmusvaara (1999), mentions that cost or profit based optimization with capacity restrictions is the most widely used method for supply chain network design. Today's business environment require more customer driven approaches by using associated techniques like AHP, DEA etc. In this respect, Korpela and Lehmusvaara (1999) stated that, MILP, mixed integer linear programming can also be adaptive for increasing the advantages of the selecting the site of the location of plant and warehouse. Thus, the plant and warehouse, two important facilities of the supply chain network, can be located 
THE LOCATION PROBLEM OF A PLANT AND

A WAREHOUSE BY AN EXPANDED

LINEAR PROGRAMMING MODEL INTEGRATED WITH AHP

based on multiple quantitative and qualitative criteria instead of just only costs or profits. 


\section{METHODOLOGY}

1. The facility location factors are listed.

2. The factors are grouped as quantitative and qualitative.

3. The quantitative factors are based on cost categories and each alternative has a cost value from each cost category.

4. Each cost value at each cost category is normalized and weighted inversely proportional to the cost. These normalized numbers will become coefficients in step 6 at the linear integer programming model.

5. The general criteria are stated and then AHP is applied and as a result weight for each qualitative factor is noted in order to be used as a coefficient in the step

6. General linear integer programming model is designed with a Maximizing objective function; weights coming from cost figures become the coefficients of the quantitative factors and weights coming from the AHP become the coefficients of qualitative factors.

Step1: The plant or facility location problem enlarged to a form of location problem for all network including warehouses and suppliers as well. The global competition enforces firms to operate global business operations in which location problem becomes a global problem. As a result of this global perspective the factors associated to location factors contains global factors as well as local factors.

- Government Stability

- Exchange Rates

- Export \& Import Regulations

- Labour force \& Education

- Labour cost

- Proximity to customers

- No. of customers

- Construction \& leasing costs

- Land cost

- Modes and quality of transport
- Transportation costs

- Community attitude

- Incentive packages

- Environmental regulations

- Raw material availability

- Infrastructure

- Quality of life

- Tax

- Proximity of suppliers

- Holding costs

Step2: The location factors are classified as quantitative (cost oriented) and qualitative factors.

Quantitative

- Labour cost

- Land cost

- Exchange Rates

- Holding costs

- Export \& Import Regulations

- Incentive packages 
THE LOCATION PROBLEM OF A PLANT AND

A WAREHOUSE BY AN EXPANDED

LINEAR PROGRAMMING MODEL INTEGRATED WITH AHP

- Tax

- Transportation costs

- Construction \& leasing costs

Qualitative

- Modes and quality of transport

- Infrastructure

- Proximity to customers

- Community attitude

- No. of customers

- Government Stability

- Quality of life

- Environmental regulations

- Labour force \& Education

- Raw material availability

- Proximity to competitors

- Proximity of suppliers

Step3: For each plant location alternative and for each warehouse location alternative the total cost amounts are calculated at each cost category.

Step4: Then each alternative are normalized inversely proportional to the amount of cost. So each alternative has a coefficient at each cost category and these coefficients sum up to 1 .

Land cost

$\mathrm{LC}_{\mathrm{pi}}=\mathrm{SI}_{\mathrm{pi}} \mathrm{LA}_{\mathrm{pi}}$

$\mathrm{SI}_{\mathrm{pi}}=$ size of plant in site $\mathrm{i}$

$\mathrm{LA}_{\mathrm{pi}}=$ unit land cost of plant at site $\mathrm{i}$

$\mathrm{LC}_{\mathrm{pi}}=$ total land cost of plant at site $\mathrm{i}$

$\alpha \mathrm{LC}_{\mathrm{pi}}=$ inversely normalized, will be denoted with $\mathrm{afi}$ in linear int. prog. model

$\mathrm{LC}_{\mathrm{wi}}=\mathrm{SI}_{\mathrm{wi}} \mathrm{LC}_{\mathrm{wi}}$

$\mathrm{SI}_{\mathrm{wi}}=$ size of warehouse in site $\mathrm{i}$

$\mathrm{LA}_{\mathrm{wi}}=$ unit land cost of warehouse at site $\mathrm{i}$

$\mathrm{LC}_{\mathrm{wi}}=$ total land cost of warehouse at site $\mathrm{i}$

$\alpha \mathrm{LC}_{\mathrm{wi}}=$ inversely normalized, will be denoted with $\mathrm{S} f \mathrm{fm}$ in linear int. prog. model

Labour cost

$\mathrm{LBC}_{\mathrm{pi}}=\mathrm{LR}_{\mathrm{pi}} \mathrm{LB}_{\mathrm{pi}}$

$\mathrm{LR}_{\mathrm{pi}}=$ labour requirement for plant at site $\mathrm{i}$

$\mathrm{LB}_{\mathrm{pi}}=$ unit labour cost of plant at site $\mathrm{i}$

$\mathrm{LBC}_{\mathrm{pi}}=$ total labour cost of plant at site $\mathrm{i}$

$\alpha \mathrm{LBC}_{\mathrm{pi}}=$ inversely normalized, will be denoted with $\mathrm{afi}$ in linear int. prog. model 
$\mathrm{LBC}_{\mathrm{wi}}=\mathrm{LR}_{\mathrm{wi}} \mathrm{LB}_{\mathrm{wi}}$

$\mathrm{LR}_{\mathrm{wi}}=$ labour requirement for warehouse at site $\mathrm{i}$

$\mathrm{LB}_{\mathrm{wi}}=$ unit labour cost of warehouse at site $\mathrm{i}$

$\mathrm{LBC}_{\mathrm{wi}}=$ total labour cost of warehouse at site $\mathrm{i}$

$\alpha \mathrm{LBC}_{\mathrm{wi}}=$ inversely normalized, will be denoted with $\mathrm{Sfm}$ in linear int. prog. model

Construction cost

$\mathrm{CNC}_{\mathrm{pi}}=\mathrm{BR}_{\mathrm{pi}} \mathrm{CN}_{\mathrm{pi}}$

$\mathrm{BR}_{\mathrm{pi}}=$ building requirements for plant at site $\mathrm{i}$

$\mathrm{CN}_{\mathrm{pi}}=$ unit construction cost of plant at site $\mathrm{i}$

$\mathrm{CNC}_{\mathrm{pi}}=$ total construction cost of plant at site $\mathrm{i}$

$\alpha \mathrm{CNC}_{\mathrm{pi}}=$ inversely normalized, will be denoted with afi in linear int. prog. model

$\mathrm{CNC}_{\mathrm{wi}}=\mathrm{BR}_{\mathrm{wi}} \mathrm{CN}_{\mathrm{wi}}$

$\mathrm{BR}_{\mathrm{wi}}=$ building requirements for warehouse at site $\mathrm{i}$

$\mathrm{CN}_{\mathrm{wi}}=$ unit construction cost of warehouse at site $\mathrm{i}$

$\mathrm{CNC}_{\mathrm{wi}}=$ total construction cost of warehouse at site $\mathrm{i}$

$\alpha \mathrm{CNC}_{\mathrm{wi}}=$ inversely normalized, will be denoted with $\mathrm{S} f \mathrm{fm}$ in linear int. prog. model

Transportation cost

$\sum_{t=1}^{n} q_{t} t s_{t} p_{i}+\sum_{j=1}^{m} q_{j}^{\prime} t^{\prime} p_{i} w_{j}=\mathrm{TS}_{\mathrm{t}} \mathrm{W}_{\mathrm{j}} \mathrm{P}_{\mathrm{i}}$

$\mathrm{q}_{\mathrm{t}}=$ quantity send from supplier $\mathrm{t}$ to plant at site $\mathrm{i}$

$\mathrm{ts}_{\mathrm{t}} \mathrm{p}_{\mathrm{i}}=$ unit transportation cost from supplier $\mathrm{t}$ to plant at site $\mathrm{i}$

$\mathrm{q}_{\mathrm{j}}^{\prime}=$ quantity send from plant at site $\mathrm{i}$ to warehouse at site $\mathrm{i}$

$\mathrm{t}^{\prime} \mathrm{p}_{\mathrm{i}} \mathrm{W}_{\mathrm{j}}=$ unit transportation cost from plant at site $\mathrm{i}$ to warehouse at site $\mathrm{i}$

$\mathrm{TS}_{\mathrm{t}} \mathrm{W}_{\mathrm{j}} \mathrm{P}_{\mathrm{i}}=$ total transportation cost from supplier to plant at site $\mathrm{i}$ and from plant at site $i$ to warehouse at site $i$.

$\alpha \mathrm{TS}_{\mathrm{t}} \mathrm{W}_{\mathrm{j}} \mathrm{P}_{\mathrm{i}}=$ inversely normalized, will be denoted with $\mathrm{a}_{\mathrm{fi}}$ in linear int. prog. model 
THE LOCATION PROBLEM OF A PLANT AND

A WAREHOUSE BY AN EXPANDED

$\sum_{j=1}^{m} k_{j} t w_{i} b_{j}=\mathrm{TW}_{\mathrm{i}} \mathrm{B}_{\mathrm{j}}$

$\mathrm{k}_{\mathrm{j}}=$ quantity send from warehouse at site $\mathrm{i}$ to market $\mathrm{j}$

$\mathrm{tw}_{\mathrm{i}} \mathrm{b}_{\mathrm{j}}=$ unit transportation cost from warehouse at site $\mathrm{i}$ to market $\mathrm{j}$

$\mathrm{TW}_{\mathrm{i}} \mathrm{B}_{\mathrm{j}}=$ total transportation cost from warehouse at site $\mathrm{i}$ to market $\mathrm{j}$

$\alpha \mathrm{TW}_{\mathrm{i}} \mathrm{B}_{\mathrm{j}}=$ inversely normalized, will be denoted with $\mathrm{S} f \mathrm{~m}$ in linear int. prog.

model

Export \& import regulations

$\sum_{t=1}^{n} x_{i} r s_{t} p_{i}+\sum_{j=1}^{m} d_{j} z p_{i} w_{j}=\operatorname{TIS}_{\mathrm{t}} \mathrm{P}_{\mathrm{i}} \mathrm{W}_{\mathrm{j}}$

$\mathrm{X}_{\mathrm{i}}=$ quantity send from supplier $\mathrm{t}$ to plant at site $\mathrm{i}$.

$\mathrm{rs}_{\mathrm{t}} \mathrm{p}_{\mathrm{i}}=$ import \& export cost per unit send from supplier $\mathrm{t}$ to plant at site $\mathrm{i}$.

$\mathrm{d}_{\mathrm{j}}=$ quantity send from plant at site $\mathrm{i}$ to warehouse at site $\mathrm{j}$

$\mathrm{Zp}_{\mathrm{i}} \mathrm{W}_{\mathrm{j}}=$ import \& export cost per unit send from plant at site i to warehouse at site j

$\mathrm{TIS}_{\mathrm{t}} \mathrm{P}_{\mathrm{i}} \mathrm{W}_{\mathrm{j}}=$ total import \& export cost of materials send from supplier $\mathrm{t}$ to plant at site $\mathrm{i}$ and from plant at site $\mathrm{i}$ to warehouse at site $\mathrm{j}$.

$\alpha$ TIS $_{\mathrm{t}} \mathrm{P}_{\mathrm{i}} \mathrm{W}_{\mathrm{j}}=$ inversely normalized, will be denoted with afi in linear int. prog. model

$\sum_{j=1}^{m} g_{j} r w_{i} c_{j}=\mathrm{TIW}_{\mathrm{i}} \mathrm{C}_{\mathrm{j}}$

$\mathrm{g}_{\mathrm{i}}=$ quantity send from warehouse at site $\mathrm{i}$ to customer $\mathrm{j}$.

$\mathrm{rw}_{\mathrm{i}} \mathrm{c}_{\mathrm{j}}=$ import\&export cost per unit send from warehouse at site $\mathrm{i}$ to customer $\mathrm{j}$.

$\mathrm{TIW}_{\mathrm{i}} \mathrm{C}_{\mathrm{j}}=$ total import\&export cost of materials send from warehouse at site $\mathrm{i}$ to customer j.

$\alpha$ TIW $_{\mathrm{i}} \mathrm{C}_{\mathrm{j}}=$ inversely normalized, will be denoted with $\mathrm{S} f \mathrm{~m}$ in linear int. prog. model

Inventory holding cost

$(\mathrm{HC})_{\mathrm{i}} \mathrm{V}_{\mathrm{i}} \mathrm{P}_{\mathrm{i}}=$ annual inventory cost for plant at site $\mathrm{i}$

$(\mathrm{HC})_{\mathrm{i}}=$ annual inventory holding cost for plant at site $\mathrm{i}$.

$\mathrm{V}_{\mathrm{i}} \mathrm{P}_{\mathrm{i}}=$ annual amount of inventory hold at plant at site $\mathrm{i}$

$\alpha(\mathrm{HC})_{\mathrm{i}} \mathrm{V}_{\mathrm{i}} \mathrm{P}_{\mathrm{i}}=$ inversely normalized, will be denoted with $\mathrm{afi}$ in linear int. prog. model 
$(\mathrm{HC})_{\mathrm{j}} \mathrm{V}_{\mathrm{j}} \mathrm{W}_{\mathrm{j}}=$ annual inventory cost for warehouse at site $\mathrm{j}$

$(\mathrm{HC})_{\mathrm{j}}$ annual inventory holding cost for warehouse at site $\mathrm{j}$.

$\mathrm{V}_{\mathrm{j}} \mathrm{W}_{\mathrm{j}}=$ annual amount of inventory hold at warehouse at site $\mathrm{j}$

$\alpha(\mathrm{HC})_{\mathrm{j}} \mathrm{V}_{\mathrm{j}} \mathrm{W}_{\mathrm{j}}=$ inversely normalized, will be denoted with $\mathrm{afi}$ in linear int. prog. model

$\operatorname{Tax}$

$\mathrm{TX}_{\mathrm{j}} \mathrm{P}_{\mathrm{i}}=$ tax with kind $\mathrm{j}$ applied to plant at site $\mathrm{i}$

$\mathrm{X}_{\mathrm{j}}=$ tax with kind $\mathrm{j}$

$\alpha \mathrm{TX}_{\mathrm{j}} \mathrm{P}_{\mathrm{i}}=$ inversely normalized, will be denoted with $\mathrm{a}$ fi in linear int. prog. model

$\mathrm{TX}_{\mathrm{j}} \mathrm{W}_{\mathrm{i}}=$ tax with kind $\mathrm{j}$ applied to warehouse at site $\mathrm{i}$

$\mathrm{X}_{\mathrm{j}}=$ tax with kind $\mathrm{j}$

$\alpha \mathrm{TX}_{\mathrm{j}} \mathrm{W}_{\mathrm{i}}=$ inversely normalized, will be denoted with $\mathrm{Sfm}$ in linear int. prog. model

Insurance cost

$(\mathrm{TIN})_{\mathrm{j}} \mathrm{P}_{\mathrm{i}}=$ insurance with kind $\mathrm{j}$ applied to plant at site $\mathrm{i}$

$(\mathrm{TIN})_{\mathrm{j}}=$ insurance with kind $\mathrm{j}$

$\alpha(\mathrm{TIN})_{\mathrm{j}} \mathrm{P}_{\mathrm{i}}=$ inversely normalized, will be denoted with $\mathrm{a}_{\mathrm{fi}}$ in linear int. prog. model

$(\mathrm{TIN})_{\mathrm{j}} \mathrm{W}_{\mathrm{i}}=$ insurance with kind $\mathrm{j}$ applied to warehouse at site $\mathrm{i}$

$(\mathrm{TIN})_{\mathrm{j}}=$ insurance with kind $\mathrm{j}$

$\alpha(\mathrm{TIN})_{\mathrm{j}} \mathrm{W}_{\mathrm{i}}=$ inversely normalized, will be denoted with $\mathrm{S} f \mathrm{fm}$ in linear int. prog. model

Incentive packages

$(\mathrm{TIP})_{\mathrm{j}} \mathrm{P}_{\mathrm{i}}=$ insurance with kind $\mathrm{j}$ applied to plant at site $\mathrm{i}$

$(\mathrm{TIP})_{\mathrm{j}}=$ incentive package with kind $\mathrm{j}$

$(\mathrm{TIP})_{\mathrm{j}} \mathrm{P}_{\mathrm{i}}=$ normalized, will be denoted with $\mathrm{a}_{\mathrm{f}}$ in linear int. prog. model

$(\mathrm{TIP})_{\mathrm{j}} \mathrm{W}_{\mathrm{i}}=$ insurance with kind $\mathrm{j}$ applied to warehouse at site $\mathrm{i}$

$(\mathrm{TIP})_{\mathrm{j}}=$ incentive package with kind $\mathrm{j}$

$(\mathrm{TIP})_{\mathrm{j}} \mathrm{W}_{\mathrm{i}}=$ normalized, will be denoted with $\mathrm{Sfm}$ in linear int. prog. model 
THE LOCATION PROBLEM OF A PLANT AND

A WAREHOUSE BY AN EXPANDED

LINEAR PROGRAMMING MODEL INTEGRATED WITH AHP

Step5: AHP, Analytical Hierarchy Process, (Saaty and Bennet (1979) and Saaty 1990) which is used to calculate the weights for $b_{h i}, r_{h e}$ which will be used in the formula in evaluating the alternative factory and warehouse site location alternatives. The form seen in Figure 2 is filled in order to be used in AHP in order to compare 14 qualitative factors in pair wise. Then the weights for each criterion, $b_{h i}$ for plant, $r_{h e}$ for warehouse are calculated as following:

A. The normalized form of pair wised comparison of the 14 factors are added as row wised.

B. Then in Figure 3 the pair wised comparisons of the site alternatives for each of the factor are made. Afterwards the weights are calculated for each alternative.

C. The weights calculated in A. and B. are multiplied then normalized as seen in Figure 3.

D. The weights for each alternative associated to the first factor are calculated and ready to be placed in the model.

The same calculations are applied to all of the 14 criteria for each of plant and warehouse site alternatives.

Figure 1

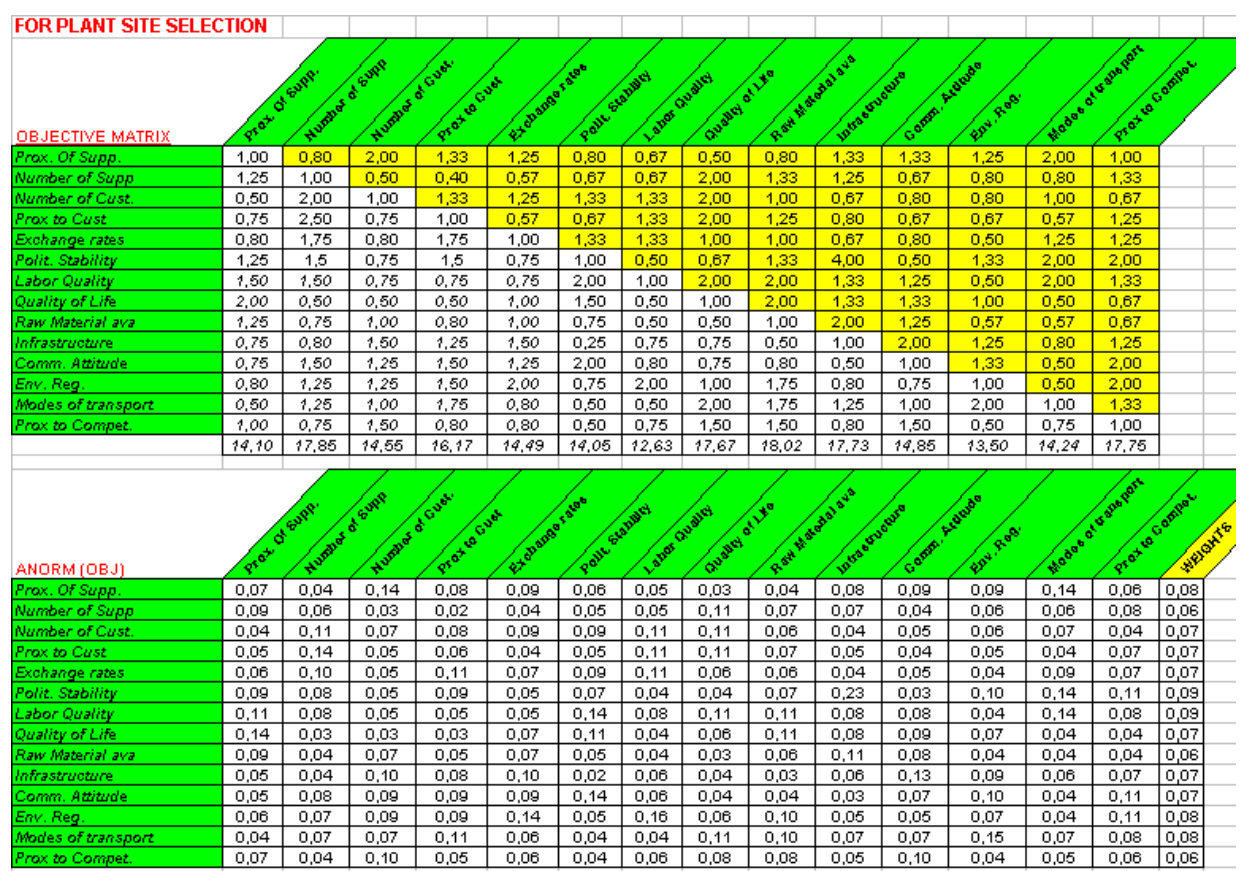


The AHP procedure for 14 factors, in the application phase, consistency of the tables are checked then solved and a coefficient for each location factor is calculated for the criteria 1 as seen in Figure 2 . The total score values will be used in the final linear integer programming model as the coefficients of the qualitative location factors.

Figure 2

\begin{tabular}{|c|c|c|c|c|c|c|c|c|c|c|c|}
\hline CRITERIA 1 (h1) & & & & & & & & & & & \\
\hline Prox. Of Supp.Matrix & $11 \mathrm{CHSL}$ & 12 KPASA & 13 MEIID & 14 TOREALI & 15 ALIAGA & IS TIRE & & & & & \\
\hline i1 CIGLI & 1,00 & 0,33 & 2,00 & 0,80 & 0,50 & 1,33 & & & & & \\
\hline i2 KEMALPASA & 3,00 & 1,00 & 1,33 & 1,25 & 1,25 & 0,50 & & & & & \\
\hline i3 MENDERES & 0,50 & 0,75 & 1,00 & 0,83 & 0,67 & 0,80 & & & & & \\
\hline i4 TORBALI & 1,25 & 0,80 & 1,20 & 1,00 & 0,80 & 0,80 & & & & & \\
\hline i5 ALIAGG & 2,00 & 0,80 & 1,50 & 1,25 & 1,00 & 1,33 & & & & & \\
\hline \multirow[t]{2}{*}{ i6 TIRE } & 0,75 & 2,00 & 1,50 & 1,25 & 0,75 & 1,00 & & & & & \\
\hline & 8,50 & 2,88 & 5,53 & 3,88 & 3,22 & 3,43 & & & & & \\
\hline & & & & & & & & & & & \\
\hline & & & & & & & & & & & \\
\hline Anom Prox. of Supp.Matrix & $11 \mathrm{CrSL}$ & 12 KPASA & IS MEIID & I4 TOREALI & 115 AL LAGA & II TIRE & & & & & bhi \\
\hline i1 CIGLI & 0,12 & 0,12 & 0,36 & 0,21 & 0,16 & 0,39 & 0,20 & & \begin{tabular}{|l|}
0,0151 \\
\end{tabular} & \begin{tabular}{|l|}
0,1365 \\
\end{tabular} & b11 \\
\hline i2 KEMALPASA & 0,35 & 0,35 & 0,24 & 0,32 & 0,39 & 0,15 & 0,32 & & \begin{tabular}{|l|}
0,0189 \\
\end{tabular} & 0,1701 & $\mathrm{~b} 12$ \\
\hline i3 MENDERES & 0,06 & 0,26 & 0,18 & 0,21 & 0,21 & 0,23 & 0,18 & & 0,0129 & 0,1165 & b13 \\
\hline i4 TORBALI & 0,15 & 0,28 & 0,22 & 0,26 & 0,25 & 0,23 & 0,22 & & \begin{tabular}{|l|}
0,0150 \\
\end{tabular} & 0,1349 & b14 \\
\hline i5 ALIAGA & 0,24 & 0,28 & 0,27 & 0,32 & 0,31 & 0,39 & 0,28 & & 0,0195 & 0,1757 & b15 \\
\hline \multirow{2}{*}{ i6 TIRE } & 0,09 & 0,69 & 0,27 & 0,32 & 0,23 & 0,29 & 0,34 & & \begin{tabular}{|l|}
0,0295 \\
\end{tabular} & \begin{tabular}{|l|}
0,2663 \\
\end{tabular} & b16 \\
\hline & & & & & & & & & 0,1109 & 1,00 & \\
\hline
\end{tabular}

STEP6: As an application the problem requires to select one site for the plant and one site for the warehouse. The integer linear programming model will enable us to combine qualitative and quantitative factors in the same methodology which is based on operations research. Weighting general categories, qualitative and quantitative, there can be a coefficient assigned as a weight to quantitative factors denoted by $\beta$ and $1-\beta$ to qualitative factors.

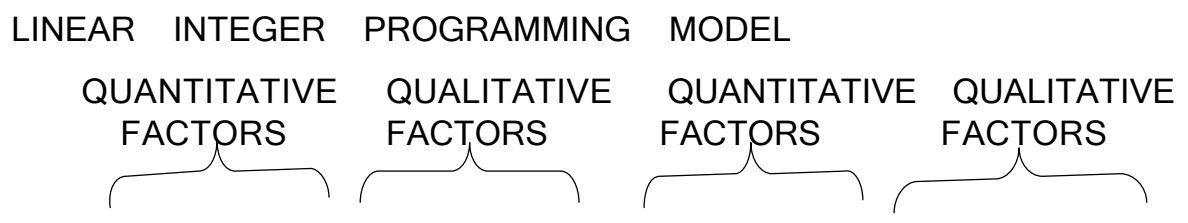


THE LOCATION PROBLEM OF A PLANT AND

A WAREHOUSE BY AN EXPANDED

LINEAR PROGRAMMING MODEL INTEGRATED WITH AHP

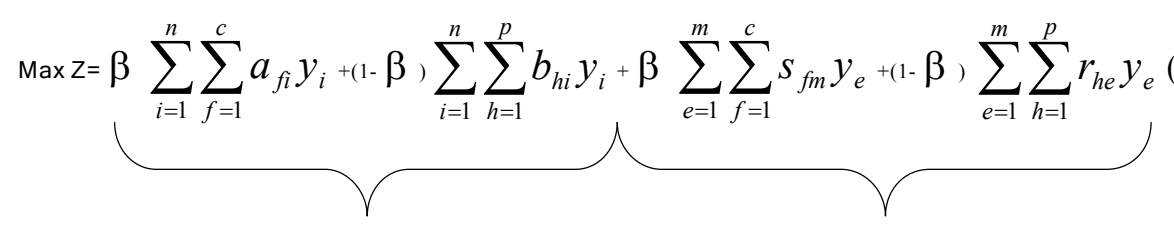

FOR PLANT LOCATION

FOR WAREHOUSE LOCATION

s.t.

$\sum_{i=1}^{n} y_{i}=1$

$\sum_{e=1}^{m} y_{e}=1$

$\mathrm{y}_{\mathrm{i}}, \mathrm{y}_{\mathrm{e}}=0$ or 1

$\mathrm{a}_{\mathrm{fi}}, \mathrm{b}_{\mathrm{hi}}, \mathrm{s}_{\mathrm{fm}}, \mathrm{r}_{\mathrm{he}}>=0$

\section{APPLICATION ON THE INDUSTRY}

The proposed linear model in this paper is applied to a steel construction firm with a plan of establishing a plant, where it can produce the custom based orders of the customers, and a warehouse, where the firm can sell the steel sheets to customers as a raw material. In this case steel sheets are the raw materials for the plant and at the same time product for the warehouse where the sales will be conducted. It is possible to define the plant as a potential customer of the warehouse as well.

The six alternatives for plant and six alternatives for warehouse locations are in city of Izmir according to the investment plans of the investors. There are provinces which are providing a plant and a warehouse alternative at the same time.

Site alternatives for the plant (i):

Cigli, Kemalpasa, Menderes, Torbali, Aliaga, Tire

Site alternatives for the warehouse (e):

Cigli, Kemalpasa, Menderes, Torbali, Pinarbasi, Isikkent

Figures 1-2 are prepared in the application phase of this study. The linear integer model is solved in Lingo Software. As the results of the application, the selected site for the plant location came out to be Menderes and Pinarbasi for the warehouse location. 


\section{CONCLUSION}

The study stands on one of the most strategic actions taken by the management, facility location decision. It is implied that the facility location problem should be based on the systems approach and for the problem both plant and warehouse locations can be discussed as a whole. In global competition as strategic management implies long-term aims should be stated. So for success limiting the management with just a certain number of criteria can be misleading for the global competition.

The study mentions the importance of qualitative factors, which is an important point in the management as well as quantitative factors because it would be a failure to be based solely on qualitative factors. The vice versa is also true that depending solely on quantitative factors would also be a reason for a failure. Especially in strategic decisions like facility location the importance of the accuracy increases. As a result the need for a new way of thinking and a new methodology is required for the management in order to combine quantitative and qualitative factors.

The methodology in the study is a combination of both qualitative and quantitative factors. Initially the factors are stated and then they are grouped into quantitative and qualitative factor. Then the quantitative factors are modelled based on the cost figures and then inversely normalized in order to assign a coefficient to each factor to be used in the linear integer programming model. Then the qualitative factors are subject to AHP. The result of the AHP became the coefficients of the qualitative factors to be used in the linear integer programming model.

The linear integer-programming model is based on MAX objective, which implies the difference between the MIN objective of the previous techniques which were solely based on minimization of the costs. Therefore the combination of qualitative and quantitative factors is succeeded through the techniques of operational research. Future research should be conducted and field studies can be applied using this methodology enabling the researchers the applicability of the methodology. The methodology and the models can also be enlarged to cover more points of the supply chain and more factors can also be added.

\section{REFERENCES}

ATTHIRAWONG, W., MACCARTHY, B.L., 2003, Factors affecting location decisions in international operations - a Delphi study, International Journal of Operations \& Production Management, Volume 23 No. 7, pp.794-818. 
THE LOCATION PROBLEM OF A PLANT AND

A WAREHOUSE BY AN EXPANDED

LINEAR PROGRAMMING MODEL INTEGRATED WITH AHP

ARYA, V., GARG, N., KHANDEKAR R., MEYERSON, A., MUNAGALA, K., PANDIT V., 2004, Local Search Heuristics for k-Median and Facility Location Problems, Society for Industrial and Applied Mathematics, pp.544-562.

CHEN, C., W., SHA, D., Y., 2001, A new approach to the multiple objective facility layout problem, Journal of Integrated Manufacturing Systems, pp.59-66.

CHUANG, P., T., A QFD, 2002, Approach for Distribution Location Model, International Journal of Quality and Reliability Management, Volume 19,No.8/9, pp.1037-54.

CURRENT, J.S., REVELLE C., 1998, European Journal on Operation Research, Volume 110 Issue 3, pp.597-610.

HOFFMAN, J., SCHNIEDERJANS, M., 1994, "A two-stage model for structuring global facility site selection decisions", International Journal of Operations \& Production Management, Volume 14, No. 4, pp.79-96.

JAYARAMAN V., 1998, "Transportation, facility location and inventory issues in distribution network design", an investigation; International Journal of Operations \& Production Management, Volume 18 No. 5, pp.471-494, MCB University Press, 0144-357.

JUNGTHIRAPANICH, C., BENJAMIN, C., 1995, "A knowledge-based decision support system for locating a manufacturing facility", IIE Transactions, Volume 27, pp.789-99.

KORPELA, J., LEHMUSVAARA A., 1999, International Journal of Production Economics, Volume 59 Issue 1-3, pp.135-147.

KUMRAL M., 2004, Optimal location of a mine facility by genetic algorithms, Mining Technology, Trans. Inst. Min. Metall. June, Volume 113 pp.83

LAPORTE G., REVELLE C. S., 1996, The plant location problem: new models and search prospects, Operations Research Journal, Volume 44. No: 6.

MILLS J., SCHMITZ J., FRIZELLE G., 2004, International Journal of Operations \& Production Management, Volume 24 No. 10, pp.1012-1036.

SAATY, T.L., BENNET, J.P. (1979). A Theory of Analytical Hierarchies Applied to Political Candidacy. Behavioral Science, Vol 22, s.237-245.

SAATY, T.L., "How to Make a Decision: The Analytic Hiearrchy Process", European Journal of Operational Research, 1990:48,s.9-26.

TOLOKEN, S., 2000, Plastics News, Volume 11 Issue 49, pp.19-20

VERTER, V., DINÇER, C., 1995, Facility location and capacity acquisition: an integrated approach. Naval Research Logistics, Volume 42, pp.1141-1160. 